\title{
Periplocoside A prevents experimental autoimmune encephalomyelitis by suppressing IL-17 production and inhibits differentiation of Th17 cells
}

\author{
Jing ZHANG ${ }^{1}$, Jia NI ${ }^{1}$, Zhen-hua CHEN ${ }^{2}$, Xin $\mathrm{LI}^{1}$, Ru-jun ZHANG ${ }^{2}$, Wei TANG ${ }^{1}$, Wei-min ZHAO ${ }^{2, *}$, Yi-fu YANG ${ }^{3, *}$, Jian-ping
} $\mathrm{ZUO}^{1,3, *}$

${ }^{1}$ State Key Laboratory of New Drug Research, ${ }^{2}$ Department of Natural Products Chemistry, Shanghai Institute of Materia Medica, Chinese Academy of Sciences, Shanghai 201203, China; ${ }^{3}$ Laboratory of Immunology \& Virology, Shanghai University of Traditional Chinese Medicine, Shanghai 201203, China

\begin{abstract}
Aim: The aim of this study was to determine the therapeutic effect of Periplocoside A (PSA), a natural product isolated from the traditional Chinese herbal medicine Periploca sepium Bge, in MOG $_{35-55}$ (myelin oligodendrocyte glycoprotein 35-55)-induced experimental autoimmune encephalomyelitis (EAE).

Methods: Female C57BL/6 mice immunized with $\mathrm{MOG}_{35-55}$ were treated with $(50 \mathrm{mg} / \mathrm{kg}$ or $25 \mathrm{mg} / \mathrm{kg}$ ) or without PSA following immunization and continuously throughout the study. The degree of CNS inflammation was evaluated by H\&E staining. Anti-MOG-specific recall responses were analyzed by $\left[{ }^{3} \mathrm{H}\right]$-Thymidine incorporation, ELISA, and RT-PCR. The proportion of IL-17-producing T cells was measured by flow cytometry.

Results: Oral administration of PSA significantly reduced the incidence and severity of EAE, which closely paralleled the inhibition of $\mathrm{MOG}_{35-55}$-specific IL-17 production. Importantly, PSA inhibited the transcription of IL-17 mRNA and RORyt. Further studies examining intracellular staining and adoptive transfer EAE validated the direct suppressive effect of PSA on Th17 cells. In vitro studies also showed that PSA significantly inhibited the differentiation of Th17 cells from murine purified CD4 ${ }^{+} \mathrm{T}$ cells in a dose-dependent manner. Conclusion: PSA ameliorated EAE by suppressing IL-17 production and inhibited the differentiation of Th17 cells in vitro. Our results provide new insight into the potential mechanisms underlying the immunosuppressive and anti-inflammatory effects of PSA.
\end{abstract}

Keywords: P sepium Bge; Periplocoside A; experimental autoimmune encephalomyelitis; Th17 cells

Acta Pharmacologica Sinica (2009) 30: 1144-1152; doi: 10.1038/aps.2009.101; published online 13 July 2009

\section{Introduction}

EAE is an autoimmune disease of the central nervous system (CNS) that serves as an animal model for the human disease multiple sclerosis (MS). EAE has historically been considered a disease mediated by Th1 cells. However, the demonstration that mice deficient in Th1-associated molecules, such as IFN- $\gamma^{[1,2]}$, IFN- $\gamma R^{[3,4]}$, or IL-12p35 $5^{[5]}$ develop severe EAE casts doubt on the essential function of Th1 cells in this autoimmune disease. In contrast, it seems that Th17 cells are crucial to the autoimmune pathology of EAE and collagen-induced arthritis (CIA) because mice lacking IL-17 are resistant to CIA and $\mathrm{EAE}^{[6]}$, transfer of cells that produce IL-17 results in severe

\footnotetext{
*To whom correspondence should be addressed.

E-mail jpzuo@mail.shcnc.ac.cn; wmzhao@mail.shcnc.ac.cn; yangyifu@mail.shcnc.ac.cn

Received 2009-04-09 Accepted 2009-05-27
}

disease, and treatment of mice with a neutralizing anti-IL-17 $\mathrm{mAb}$ suppresses CNS autoimmune inflammation ${ }^{[7]}$. The differentiation of Th17 cells is driven by a combination of IL-6 and TGF- $\beta 1$ signaling and maintained by the presence of IL-23. Furthermore, the retinoid-related orphan receptor $\gamma t$ (RORYt) has been identified as the key transcription factor that determines the differentiation of the Th17 lineage ${ }^{[8-10]}$.

Periploca sepium Bge is a traditional Chinese herbal medicine that is used for treating rheumatoid arthritis in China. We have previously shown the efficiency of the plant extracts in treating various autoimmune disorders, including Periplocoside E (PSE). PSE is a compound isolated from $P$ sepium Bge that inhibits EAE by suppressing chemokine receptor expression $^{[11,12]}$. Periplocoside A (PSA) is another pregnane glycoside that is relatively abundant. PSA inhibits $\mathrm{T}$ cell activation in vitro and prevents concanavalin A-induced hepatitis in mice by inhibiting NKT-derived inflammatory cytokine 
production $^{[13]}$.

No previous study has examined the effects of PSA in the treatment of EAE or other inflammatory diseases of the CNS that have been demonstrated to be mediated by Th17 cells. In the present study, we immunized C57BL/ 6 mice with $\mathrm{MOG}_{35-55}$ to induce EAE, which was considered as a T-cellmediated experimental model of chronic and non-relapsing EAE. The oral effect of PSA on EAE was examined. Our results show that oral administration of PSA significantly reduced the incidence and severity of the disease state, which was closely related to the inhibition of Th17 cells. These findings provide new insight into the potential mechanisms underlying the immunosuppressive function of PSA and suggest a promising therapeutic effect for PSA treatment of human MS.

\section{Materials and methods Compounds}

PSA was extracted and purified from $P$ sepium Bge (stem barks). Briefly, powdered, air-dried root bark of $P$ sepium Bge (Asclepiadaceae) $(15 \mathrm{~kg})$ was percolated with $95 \%$ ethanol three times at room temperature. The filtrates were combined and concentrated to dryness in vacuo. The extract was suspended in water and then partitioned with chloroform to give a chloroform extract $(762.5 \mathrm{~g})$. The chloroform extract was then chromatographed over silica gel and eluted with a gradient of petroleum ether and acetone to yield the PSA extract $(2.0 \mathrm{~g})$. The purity of PSA was over $98 \%$, as determined by high-performance liquid chromatography analysis. The stock solution of PSA was prepared in dimethyl sulfoxide (DMSO) and diluted in saline with surfactant (Cremophor EL, less than $5 \%$ ) to the doses required. The final concentration of DMSO was less than $0.2 \%$.

\section{Reagents}

RPMI 1640 medium was purchased from Invitrogen (Carlsbad, CA, USA). Fetal bovine serum was purchased from Hyclone Laboratories (Logan, UT, USA). $\left[{ }^{3} \mathrm{H}\right]$-Thymidine $(1 \mathrm{mCi} / \mathrm{mL})$ was purchased from the Shanghai Institute of Atomic Energy (Shanghai, China). Bordetella pertussis toxin (PTX), 3,3',5,5'-tetramethylbenzidine, DMSO and Cremophor EL were purchased from Sigma-Aldrich (St Louis, MO, USA). Complete Freund's adjuvant (CFA) and Mycobacterium tuberculosis H37Ra were purchased from Difco (Detroit, MI, USA). The peptide $\mathrm{MOG}_{35-55}$ (MEVGWYRSPFSRVVHLYRNGK) was synthesized by Sangon Biological Engineering Technology and Service Co, Ltd (Shanghai, China). Enzyme-linked immunosorbent assay (ELISA) kits for IL-6, IL-17, IL-2, IFN- - , and anti-IFN-ץ (R4-6A2), anti-IL-4 (11B11), anti-IL-2 (JES6-1A12), anti-CD3 (145-2C11), anti-CD28 (37.51), anti-CD4 (GK1.5), anti-CD8 (2.43), IL-6, TGF- $\beta 1$, rmIL-23, rat anti-mouse CD4FITC, CD8-PE, mac1-PE, B220-PE, and IL-17-PE antibodies were obtained from BD Biosciences PharMingen (San Diego, CA, USA).

\section{Animals}

Female C57BL/6 mice (6-8-weeks old) were purchased from the Shanghai Experimental Animal Center of Chinese Academy of Sciences. Mice were housed under specific pathogenfree conditions. All mice were allowed to acclimatize in our facility for 1 week before any experiments were started. All experiments were carried out according to the National Institutes of Health Guide for Care and Use of Laboratory Animals and were approved by the Bioethics Committee of the Shanghai Institute of Materia Medica.

\section{Induction, treatment, and clinical evaluation of EAE Active EAE}

The murine active EAE model was produced as described previously $^{[14]}$. Briefly, female C57BL/6 mice were immunized on day 0 by sc injection with $100 \mu \mathrm{L}$ of an emulsion of $\mathrm{MOG}_{35-55}$ peptide in CFA containing Mycobacterium tuberculosis H37Ra. These injections were distributed over the following three sites: one along the midline of the back between the shoulders and two on either side of the midline on the lower back. The final dose of $\mathrm{MOG}_{35-55}$ and Mycobacterium tuberculosis H37Ra was 200 and $400 \mu \mathrm{g}$ per mouse. Each mouse received an additional $400 \mathrm{ng}$ of Bordetella pertussis toxin by intraperitoneal (ip) injection in $200 \mu \mathrm{L}$ of PBS on day 0 and day 3 postimmunization (pi). PSA $(50 \mathrm{mg} / \mathrm{kg}, 25 \mathrm{mg} / \mathrm{kg}$ ) and vehicle were administered orally following immunization and continuously throughout the study ( $n=10$ mice). Control mice orally received an equal volume of PBS containing $0.2 \%$ DMSO and $5 \%$ Cremophor EL $(n=10)$. Clinical assessment of EAE was performed daily and mice were scored for disease according to the following criteria: 0 , no overt signs of disease; 1 , limp tail or hind limb weakness but not both; 2 , limp tail and hind limb weakness; 3 , partial hind limb paralysis; 4 , complete hind limb paralysis; 5 , moribund state or dead ${ }^{[15]}$.

\section{IL-23-driven adoptive transfer of EAE}

The murine passive EAE model was produced as described previously with modification ${ }^{[16,17]}$. Briefly, C57BL/6 mice were immunized with $\mathrm{MOG}_{35-55}$ as previously described and then administrated vehicle or PSA $(50 \mathrm{mg} / \mathrm{kg}$ ) for $12 \mathrm{~d}$. Draining lymph node cells were harvested on day $12 \mathrm{pi}$ and cultured in the presence of $20 \mu \mathrm{g} / \mathrm{mL}$ of $\mathrm{MOG}_{35-55}$ and $20 \mathrm{ng} / \mathrm{mL}$ of rmIL-23. After 4 days, cells were harvested and washed, and purified $\mathrm{T}$ cells were transferred to naïve C57BL/ 6 mice $\left(1 \times 10^{7}\right.$ cells/mouse) via the tail vein. Mice were also given $400 \mathrm{ng}$ of pertussis toxin ip on $\mathrm{d} 0$ and $\mathrm{d} 2$ post transfer. Mice were observed daily for clinical signs of EAE up to $21 \mathrm{~d}$ after the cell transfer and scored every day according to the criteria described previously.

\section{Histopathology analysis}

To assess the degree of CNS inflammation, C57BL/ 6 mice treated with vehicle or PSA following induction of active EAE were anesthetized on day 17 (at the peak of the disease) by pentobarbital sodium and perfused by intracardiac injection of PBS containing $4 \%$ paraformaldehyde and $1 \%$ glutaraldehyde. Five-micrometer thick transverse sections were taken from cervical, upper thoracic, lower thoracic, and lumbar regions of 
the spinal cord (four sections per mouse). The sections were stained with H\&E to examine inflammation. Signs of inflammation in the anterior, posterior, and two lateral columns (four quadrants) of the spinal cord sections were scored under a light microscope as described previously ${ }^{[14]}$. Briefly, each quadrant displaying the infiltration of mononuclear cells was assigned a score of one inflammation point. Thus, each animal had a potential maximal score of 16 points of inflammation, and this study represents the analysis of ten representative mice from two different groups. The pathologic score for each group was expressed as the percentage positive over the total number of quadrants examined.

\section{Preparation of purified $\mathrm{T}$ cells and enriched antigen presenting cells (APCs)}

Primary $\mathrm{T}$ cells were purified by immunomagnetic negative selection to delete B cells and I-A ${ }^{+}$APC as described previously ${ }^{[18]}$. Lymph node cells were allowed to react with anti$\mathrm{I}-\mathrm{A}^{\mathrm{d} / \mathrm{b}} \mathrm{mAb}$ and then incubated with magnetic particles bound to goat anti-mouse Ig (Polysciences, Inc, Eppelheim, Germany). A $\mathrm{T}$ cell population depleted of anti-I-A ${ }^{\mathrm{d} / \mathrm{b}}$-labeled and surface $\mathrm{Ig}^{+}$cells was obtained by removing cell-bound magnetic particles (Polysciences, Inc). The purity of the resulting T cell populations was examined by flow cytometry with CD4FITC, CD8-PE, mac1-PE, and B220-PE antibodies and found to be consistently $>95 \%$.

Splenic antigen-presenting cell (APC)-enriched populations were separated using immunomagnetic negative selection to delete the surface $\mathrm{Ig}^{+}$cells (B cells) and T cells as described previously $^{[18]}$. Splenocytes were allowed to react with a mixture of rat anti-mouse CD4 (GK1.5) and rat anti-mouse CD8 (2.43) $\mathrm{mAb}$ and then incubated with a mixture of magnetic particles bound to goat anti-rat (Advanced Magnetics, Cambridge, MA, USA) and goat anti-mouse Ig. An APC-enriched population was obtained by removing cell-bound magnetic particles. The purity of the resulting APC-enriched populations was examined by flow cytometry with CD4-FITC, CD8-PE, mac1-PE, and B220-PE antibodies and was found to consistently include less than $1 \% \mathrm{~T}$ and $\mathrm{B}$ cells.

\section{Anti-MOG-specific immune responses}

Lymphocytes $\left(4 \times 10^{5} /\right.$ well) from draining lymph nodes (DLNs) were obtained from MOG-immunized mice with vehicle or PSA treatment and cultured in vitro with $20 \mu \mathrm{g} / \mathrm{mL}$ MOG stimulation. Supernatants were harvested at the indicated times to measure IL-6 and IL-17 levels by ELISA (BD Biosciences PharMingen). For proliferation, cells were pulsed with $1 \mu \mathrm{Ci}$ /well $\left[{ }^{3} \mathrm{H}\right]$-Thymidine for $12 \mathrm{~h}$ before harvest and assessed for $\left[{ }^{3} \mathrm{H}\right]$-Thymidine incorporation.

For antigen-presenting assay ${ }^{[18]}$, purified T cells $\left(4 \times 10^{6} /\right.$ well $)$ were obtained from MOG-immunized mice receiving vehicle or PSA treatment. Subsequently, APC-enriched cells $\left(1 \times 10^{6} /\right.$ well) were obtained from normal mice and co-cultured in 24-well flat bottom tissue culture plates in the presence of 20 $\mu \mathrm{g} / \mathrm{mL}$ of MOG and $20 \mathrm{ng} / \mathrm{mL}$ of rmIL-23. Cells were harvested at $96 \mathrm{~h}$ for flow cytometry analysis.

\section{In vitro Th17 cell differentiation and cytokine staining}

IL-17-producing CD4 ${ }^{+} \mathrm{T}$ cells were produced as described with modifications ${ }^{[19,20]}$. Lymph node cells from normal mice were allowed to react with anti-I-A ${ }^{\mathrm{d} / \mathrm{b}} \mathrm{mAb}$, as well as with antiCD8, and then were incubated with magnetic particles bound to goat anti-mouse Ig. A CD4 ${ }^{+} \mathrm{T}$ cell population depleted of $\mathrm{CD}^{+}$, anti-I-A ${ }^{\mathrm{d} / \mathrm{b}}$-labeled and surface $\mathrm{Ig}^{+}$cells was obtained by removing cell-bound magnetic particles and was found to be consistently $>95 \%$ pure. Cells were plated at a density of $4 \times 10^{6} /$ well and stimulated with anti-CD3 $(10 \mu \mathrm{g} / \mathrm{mL})$ and anti-CD28 $(2 \mu \mathrm{g} / \mathrm{mL})$. For the generation of Th17 cells, cultures were supplemented with rmIL-23 $(20 \mathrm{ng} / \mathrm{mL})$ and TGF$\beta 1$ (5 ng/mL), in combination with IL-6 (20 ng/mL). Additionally, IFN- $\gamma$ and IL-4 were neutralized in the cultures with

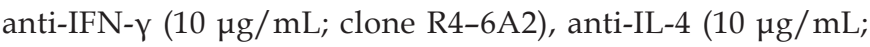
clone 11B11). For the measurement of intracellular IL-17, $\mathrm{CD}^{+} \mathrm{T}$ cells were restimulated for $5 \mathrm{~h}$ with PMA $(50 \mathrm{ng} / \mathrm{mL}$; Sigma), Ionomycin (750 ng/mL; Sigma), and Brefeldin A (10 $\mu \mathrm{g} / \mathrm{mL}$; Invitrogen) on day 4 after stimulation and stained according to the manufacturer's protocol (Becton Dickinson).

\section{Reverse transcription polymerase chain reaction analysis}

Cells were lysed with Trizol (Gibco-BRL, Gaithersburg, MD, USA) according to the manufacturer's protocol and total RNA was extracted and reverse-transcribed into cDNA as described previously ${ }^{[18]}$. cDNA were amplified and samples were separated by a $1.5 \%$ agarose gel and stained with ethidium bromide. Primers used in this study were as follows: $\beta$-actin sense, 5'-GGG AAT GGG TCA GAA GGA-3'; $\beta$-actin antisense, 5'-AAG AAG GAA GGC TGG AAA-3'; IL-17 sense, 5'-CAC CGC AAT GAA GAC C-3'; IL-17 antisense, 5'-CGA AGC AGT TTG GGA C-3'; RORyt sense, 5' -TCA CCT GAC CTA CCC GAG G-3'; RORyt antisense, 5'-TCC AAG AGT AAG TTG GCC GTC-3'; IL-23R sense, 5'-CTG GTG ACA TGT GGG TTG AG-3'; IL-23R antisense, 5'-TTC CAG GTG CAT GTC ATG TT-3'; FoxP3 sense, 5'-CTG GAT GAG AAA GGC AAG G-3'; FoxP3 antisense, 5'-AAG GGT GGC ATA GGT GAA A-3'.

\section{Statistics}

Data are shown as means \pm SEM and were analyzed using Student's t-test and one-way ANOVA with Newman-Keuls multiple comparisons on post tests. Nonparametric data (mean clinical score and histological score) were analyzed using Mann-Whitney $U$-test; $P<0.05$ was considered statistically significant.

\section{Results}

Oral administration of PSA ameliorated EAE in C57BL/6 mice

To investigate a protective effect of PSA treatment against the development of EAE, we immunized C57BL/6 mice with $\mathrm{MOG}_{35-55}$ peptide emulsified with CFA, followed by oral administration of PSA (50 and $25 \mathrm{mg} / \mathrm{kg}$ ) or vehicle on the day of immunization. All mice $(100 \%)$ in the vehicle-treated group developed severe EAE at approximately day 14.8 \pm 0.88 . In contrast, only $40 \%$ of mice treated with $50 \mathrm{mg} / \mathrm{kg}$ PSA showed 
mild signs of disease, with a delay in disease onset starting on day 16.2 \pm 1.5 (Figure 1A). Accordingly, $50 \mathrm{mg} / \mathrm{kg}$ PSA mark-
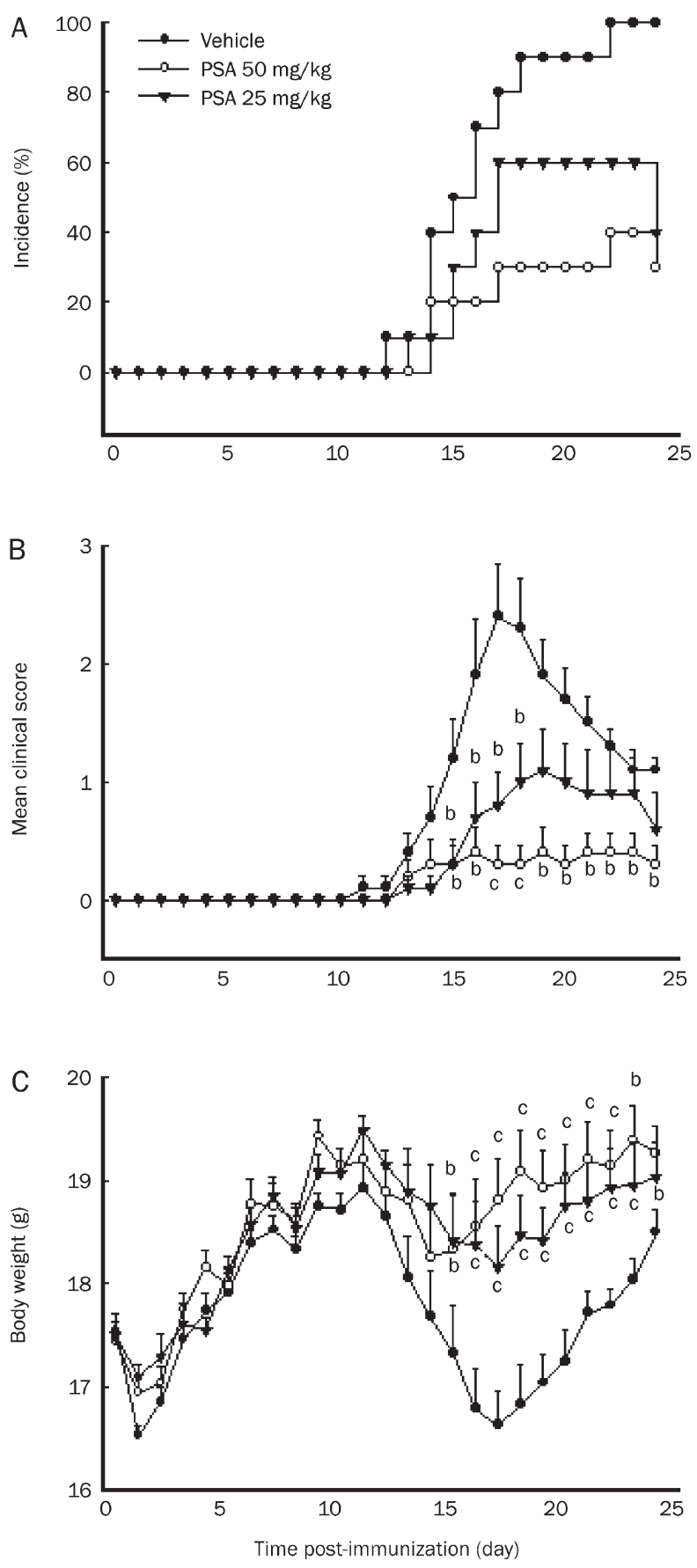

Figure 1. PSA inhibited the development of clinical signs of EAE in MOGimmunized C57BL/6 mice. Active EAE was induced in female C57BL/6 mice by immunization with $\mathrm{MOG}_{35-55}$ peptide in CFA. The mice $(n=10)$ were orally treated with vehicle or PSA $\left(50 \mathrm{mg} \cdot \mathrm{kg}^{-1} \cdot \mathrm{d}^{-1}, 25 \mathrm{mg} \mathrm{kg}^{-1} \cdot \mathrm{d}^{-1}\right)$ from d $0 \mathrm{pi}$ as detailed under Materials and methods. Mice were monitored for signs of $E A E$, and the results for all mice, both healthy and sick, were presented as a percentage of $(A)$ incidence of disease, $(B)$ mean clinical score $\pm S E M$, and $(C)$ body weight. ${ }^{b} P<0.05,{ }^{c} P<0.01$ compared with vehicle-treated control. Three independent experiments were performed with similar results. edly decreased the mean severity of EAE in PSA-treated mice (maximum mean clinical score, MMCS: vehicle group 2.4 \pm 0.45 vs PSA $50 \mathrm{mg} / \mathrm{kg}$ group $0.4 \pm 0.22, P<0.05$; Figure $1 \mathrm{~B})$. At the lower dosage of $25 \mathrm{mg} / \mathrm{kg}$, PSA exhibited a milder inhibitory effect than with the higher dose, $60 \%$ of mice treated with 25 $\mathrm{mg} / \mathrm{kg}$ PSA developed severe EAE starting on day 15.3 \pm 0.56 , which peaked on day 19 (MMCS: $1.1 \pm 0.34$ ). In addition to reducing clinical signs, oral administration of PSA also prevented the loss of body weight (Figure 1C). These results suggest that PSA inhibited the severity and duration of clinical paralysis in EAE. To investigate the underlying mechanisms of this effect, all subsequent experiments were performed with a $50 \mathrm{mg} / \mathrm{kg}$ dose of PSA.

\section{PSA reduced CNS inflammation in EAE}

We further examined the effect of PSA on CNS infiltration by analyzing spinal cord sections from vehicle and PSA treated mice. Mice treated with vehicle developed a profound inflammation in the CNS (Figure 2A, 2C), whereas treatment with $50 \mathrm{mg} / \mathrm{kg}$ PSA significantly reduced the infiltration process (Figure 2B, 2D). These results suggest that PSA inhibited CNS inflammation in EAE mice.
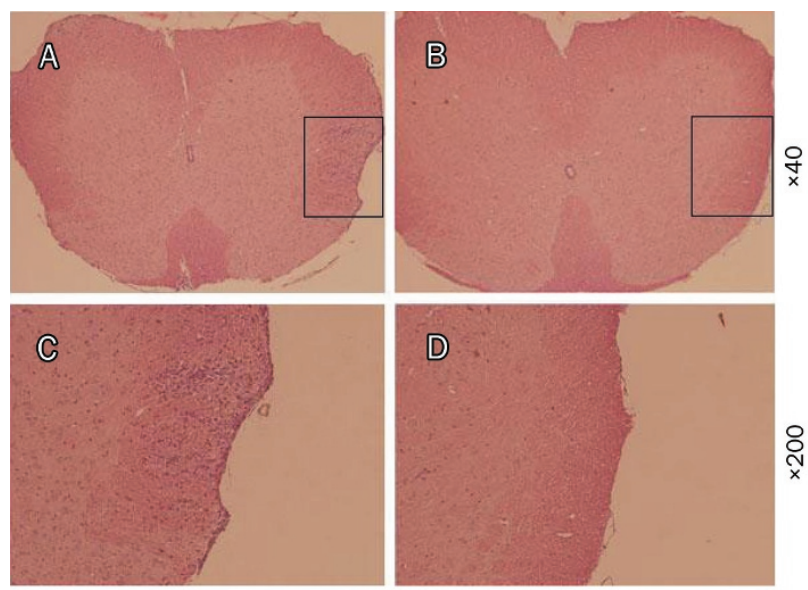

E

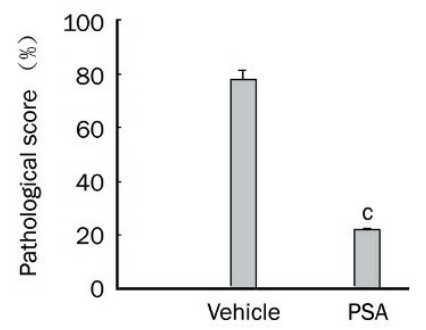

Figure 2. PSA treatment inhibited inflammatory cell infiltration in the CNS. Spinal cords were collected from EAE mice treated with vehicle (A, C) or PSA (B, D) on d 17 pi. The sections were stained with H\&E to assess inflammation. (E) The pathological score for each treatment group was expressed as a percentage over the total number of quadrants examined. Results were expressed as means \pm SEM of 10 mice. ${ }^{b} P<0.05,{ }^{c} P<0.01$ compared with vehicle control (Mann-Whitney U-test). Three independent experiments were performed with similar results. 
PSA inhibited $\mathrm{MOG}_{35-55}$ specific IL-17 production in lymphocytes from EAE mice

To investigate the change of IL-17-producing $\mathrm{T}$ cells in our EAE experimental system, we measured $\mathrm{MOG}_{35-55}$-specific production of IL-17 in ex vivo assays where lymphocytes were obtained from EAE mice at different time points, as indicated (Figure 3A). Production of IL-17 was low at the initial immunization time, increased and remained at a high level from the onset to the peak of the disease, and declined during remission.

Because days 0-14 after immunization were defined as the $\mathrm{T}$ cell expansion stage and account for the course of disease
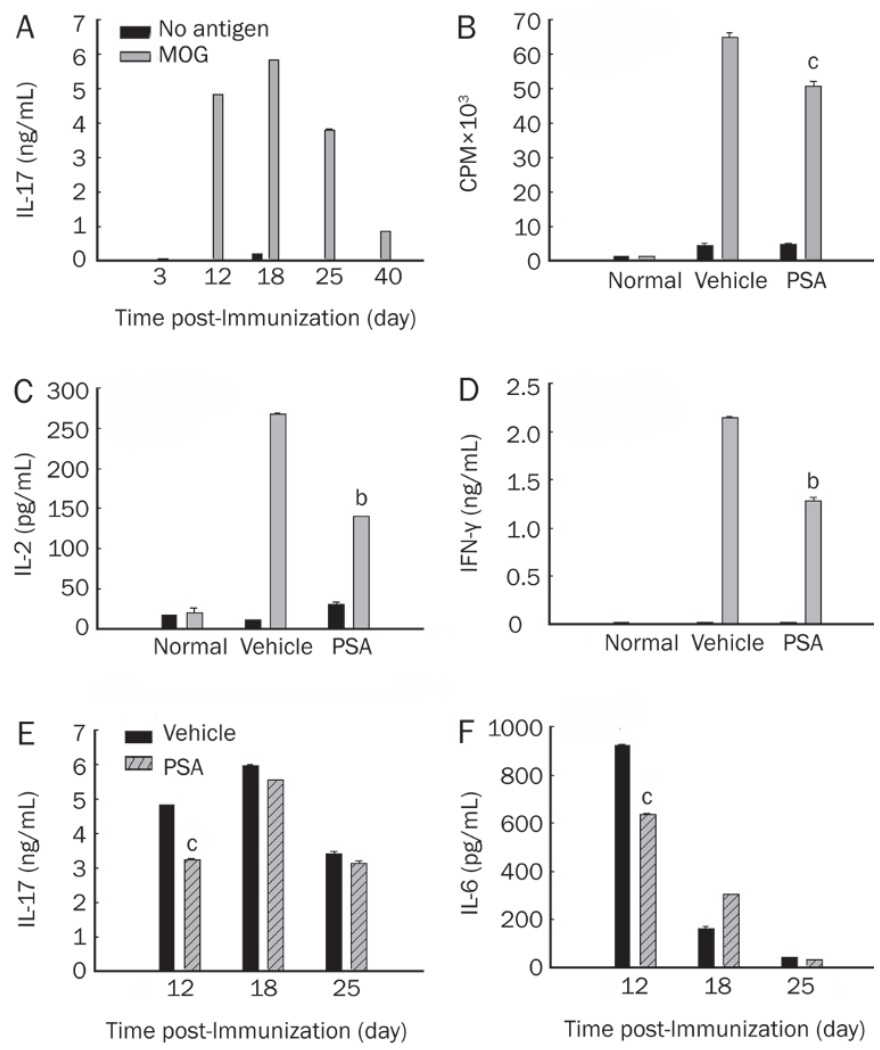

Figure 3. PSA inhibited $\mathrm{MOG}_{35-55}$-specific cytokine production and cell proliferation. (A) Time course of IL-17 production during EAE. Draining lymphocytes (DLNs) from immunized mice were isolated at the indicated time points and cultured with or without $\mathrm{MOG}_{35-55}(20 \mu \mathrm{g} / \mathrm{mL})$. Antigenspecific IL-17 production was measured at $96 \mathrm{~h}$ by ELISA. (B) On day 12 pi, DLNs from vehicle and PSA treated group (five mice per group) were incubated with or without $\mathrm{MOG}_{35-55}(20 \mu \mathrm{g} / \mathrm{mL})$ for $72 \mathrm{~h}$. Cultures were pulsed with $0.5 \mu \mathrm{Ci} /$ well $\left[{ }^{3} \mathrm{H}\right]$-Thymidine for the final $12 \mathrm{~h}$. (C, D) Culture supernatants were collected at $48 \mathrm{~h}$ to measure IL-2 and IFN-y level by ELISA. (E) DLNs from immunized mice treated with vehicle or PSA were isolated at the indicated time points and cultured with $\mathrm{MOG}_{35-55}(20 \mu \mathrm{g} /$ $\mathrm{mL}$ ). Antigen-specific IL-17 production was measured at $96 \mathrm{~h}$ by ELISA. (F) DLNs from immunized mice treated with vehicle or PSA were isolated at the indicated time points and cultured with $\mathrm{MOG}_{35-55}(20 \mu \mathrm{g} / \mathrm{mL})$. Antigen-specific IL- 6 production was measured at $48 \mathrm{~h}$ by ELISA. Results were expressed as mean \pm SEM. ${ }^{b} P<0.05,{ }^{c} P<0.01$ compared with vehicle control (unpaired Student's $t$-test). Three independent experiments were performed with similar results. in the present study, we mainly examined MOG-specific responses on day 12 (onset of EAE). As shown in Figure 3B, in vivo treatment with PSA significantly suppressed the recall responses to $\mathrm{MOG}_{35-55}$ peptide compared with vehicle-treated mice $(P<0.01)$. The production of IL-2 and IFN- $\gamma$ was significantly reduced in PSA-treated mice $(P<0.05$; Figure $3 C, 3 D)$. The production of IL-17 and IL- 6 was markedly decreased in PSA-treated mice on day $12(P<0.01)$. Reduced IL-17 production could also be detected on day 18 (peak) and day 25 (remission) in PSA-treated mice, although it did not reach a significant level (Figure 3E). In contrast, we could only detect a transient suppressive effect on IL-6 production in PSAtreated mice on day 12 (Figure 3F).

To investigate whether the protein level of the cytokine reflected changes at the RNA level, we measured the expression of mRNA encoding $I L-17$ by RT-PCR. As shown in Figure 4, the expression of IL-17 was markedly suppressed in PSAtreated mice. Because the orphan nuclear receptor RORyt is known to be the key transcription factor that orchestrates the differentiation of Th17 cells ${ }^{[9]}$, we also examined whether PSA influenced its level in MOG-immunized mice. Coincident with the change of IL-17 mRNA expression, RORyt mRNA expression in PSA-treated group revealed a marked reduction. However, FoxP3 mRNA expression was not upregulated in PSA-treated group.

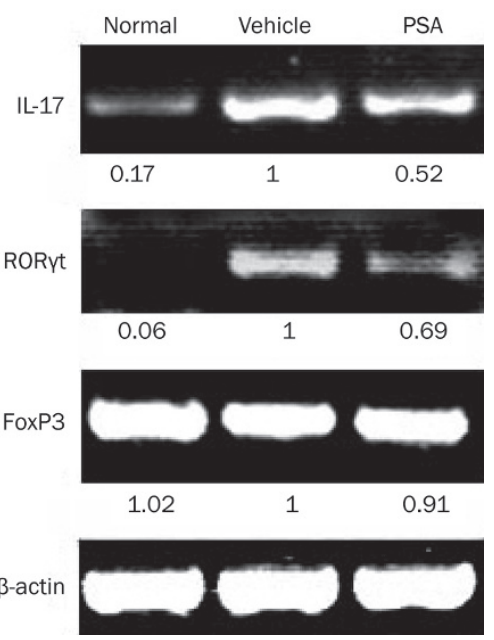

Figure 4. PSA modulated Th17 related genes expression. DLNs from normal mice, $\mathrm{MOG}_{35-55}$ immunized mice treated with vehicle or PSA were harvested on day $12 \mathrm{pi}$ and analyzed by RT-PCR for IL-17, RORyt, and FoxP3. Numbers below each lane indicate the ratio to mRNA levels from vehicle-treated cells by semiquantitative analysis. Three independent experiments were performed with similar results.

PSA ameliorated EAE due to its direct suppressive effect on Th17 cells

The inhibitory effect of PSA on the production of IL-17 might be caused by several reasons. First, a suppressive effect of PSA on cell proliferation could have caused the reduced IL-17 level in the supernatants of PSA-treated mice. Alternatively, PSA 
A

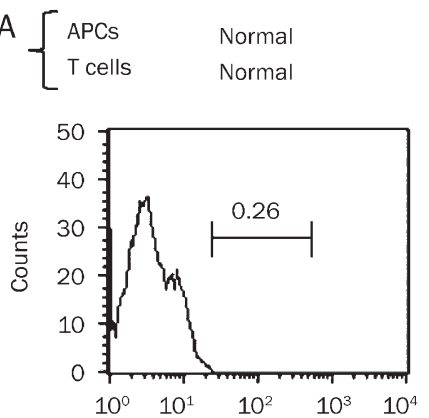

Normal

Model

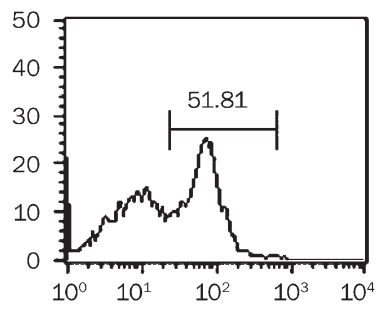

Normal

PSA

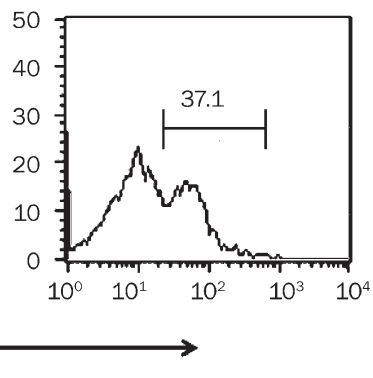

B

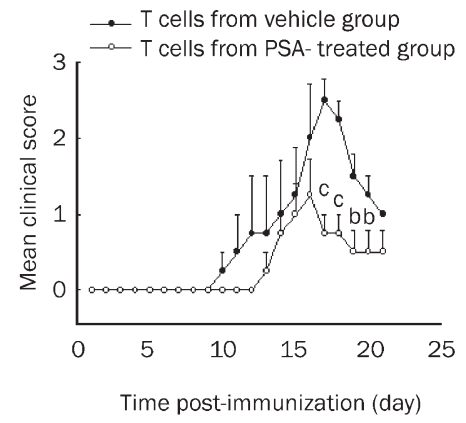

Figure 5. PSA reduced the proportion of IL-17 producing T cells in MOG-immunized mice. (A) T cells were prepared from lymph nodes by eliminating B cells and APCs. An APC-enriched population was prepared from spleen cells by eliminating T and B cells. T cells $\left(4 \times 10^{6} /\right.$ well) were cultured with APCs $\left(1 \times 10^{6} /\right.$ well) in the presence of $20 \mu \mathrm{g} / \mathrm{mL}$ of MOG and $20 \mathrm{ng} / \mathrm{mL}$ of rmlL-23 for $96 \mathrm{~h}$ to assess the intracellular proportion of IL-17 producing T cells. Numbers in quadrants indicate the percentage of positive cells in each. (B) DLNs from vehicle and PSA treated mice were harvested on $d 12$ pi and cultured in the presence of $\mathrm{MOG}_{35-55}$ and rmIL-23 for $4 \mathrm{~d}$. Purified T cells were transferred to naïve C57BL/6 mice ( $1 \times 10^{7}$ cells $\left./ \mathrm{mouse}\right)$. Mice were scored daily for clinical signs of EAE up to $21 \mathrm{~d}$ after cell transfer. Results were expressed as mean \pm SEM. ${ }^{\mathrm{b}} P<0.05,{ }^{\mathrm{c}} P<0.01 \mathrm{compared}$ with the vehicle control (unpaired Student's t-test). Three independent experiments were performed with similar results.

had a direct effect on Th17 cells. In order to try to exclude the former possibility, intracellular staining of IL-17 $\mathrm{T}$ cells was performed. Purified T cells prepared from DLNs of normal mice and $\mathrm{MOG}_{35-55}$ immunized mice treated with vehicle or PSA were stimulated with MOG $(20 \mu \mathrm{g} / \mathrm{mL})$ and rmIL-23 $(20$ $\mathrm{ng} / \mathrm{mL}$ ) in the presence of APC-enriched cells obtained from normal mice. Compared with vehicle-treated group, PSA treatment markedly reduced the proportion of IL- $17^{+} \mathrm{T}$ cells (Figure 5A).

To investigate whether the ameliorated symptoms in PSAtreated mice could be attributed to a decreased proportion of Th17 cells, MOG-specific T cells generated from mice with vehicle or PSA treatment were compared for their ability to transfer EAE. Draining lymph nodes from vehicle and PSA treated mice were prepared by immunization with $\mathrm{MOG}_{35-}$ ${ }_{55}$ and purified $\mathrm{T}$ cells were transferred following in vitro activation with $\mathrm{MOG}_{35-55}$ and rmIL-23 for $96 \mathrm{~h}$. Each normal C57BL/ 6 recipient was injected intravenously with $1 \times 10^{7} \mathrm{~T}$ cells to induce the IL-23 driven adoptive transfer EAE $(n=4)$. Clinical scores of mice that received encephalitogenic T cells showed that $\mathrm{T}$ cells from PSA-treated mice induced a less severe disease state than those from vehicle-treated group ( $2.5 \pm 0.29$ vs $1.25 \pm 0.47, P<0.05$; Figure $5 \mathrm{~B}$ ). Therefore, we concluded that PSA ameliorated EAE through its direct suppressive effect on Th17 cells.

\section{PSA inhibited the differentiation of Th17 cells in vitro}

Based on the observation that PSA had a direct suppressive effect on Th17 cells in EAE, we asked whether this was due to its inhibitory effect on Th17 cell differentiation. Purified $\mathrm{CD}^{+} \mathrm{T}$ cells were cultured for $4 \mathrm{~d}$ as described in Materials and methods. IL-17 expression was determined by intracellular staining. In the absence of PSA, the conditions generated substantial proportions of IL-17-producing cells, which were reduced by inclusion of this compound (Figure 6A). We then confirmed that this inhibition was dose dependent under Th17-polarizing conditions by ELISA (Figure 6B, black bar). We also examined the production of IL-17 in the presence of $10 \mu \mathrm{g} / \mathrm{mL}$ anti-IL-2 antibody (Figure 6B, grey bar). The neutralization efficiency of the anti-IL-2 antibody was validated by measuring IL-2 level in the culture supernatant (data not shown). We detected mRNA expression of Th17-associated genes and the mRNA expression of IL-17, RORYt, IL-23R was greatly reduced in the presence of $4 \mu \mathrm{mol} / \mathrm{L}$ PSA (Figure 6C).

\section{Discussion}

Periploca sepium Bge is a traditional Chinese herbal medicine that is used for treating rheumatoid arthritis in China. Two pregnane glycosides, PSA and PSE, have been previously studied for their immunosuppressive effects in vivo and in $v$ itro ${ }^{[11-13]}$. However, due to the low solubility of these large organic compounds, all previous studies were based on the intraperitoneal route of administration, which might impede the development of these compounds as perspective drug candidates for human autoimmune diseases. In the present study, the addition of a low concentration (less than 5\%) of Cremophor EL, which served as a nonionic surfactant, greatly improved the solubility of PSA.

In the current study, we investigated the oral effect of PSA on EAE and found that PSA ameliorated EAE through inhibiting Th17 cells. The involvement of Th17 cells in the pathogenesis of EAE not only challenged the Th1-Th2 paradigm, but also provided insights to help elucidate the mechanisms of action for these new compounds. Our previous work demonstrated that PSE inhibited EAE through suppressing Th1-subtype cytokine-dependent chemokine receptor expression ${ }^{[12]}$. Indeed, we also observed a reduced production of IL-2 and IFN- $\gamma$ in PSA-treated group in the present work (Figure 3C, 3D). However, considering that the common characteristic of natural products is that they possess multiple targets, we 
A

$\alpha \mathrm{CD} 3 / \mathrm{CD} 28$
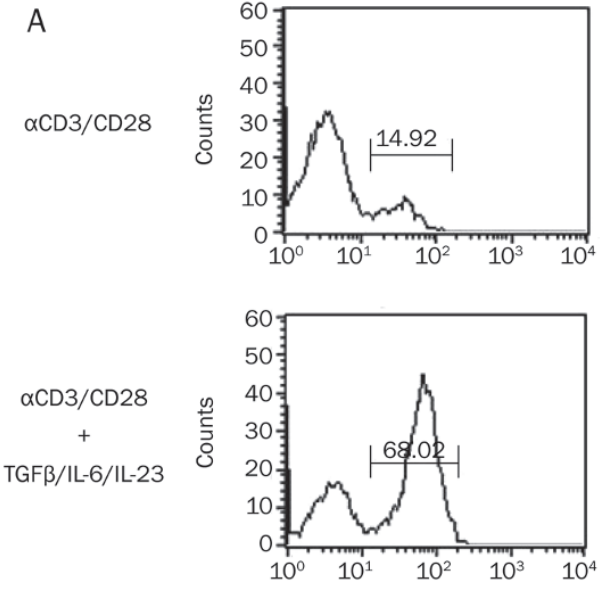

$\alpha C D 3 / C D 28$
+
TGFB/IL-6/L-23
+
PSA $(4 \mu \mathrm{mol} / \mathrm{L})$

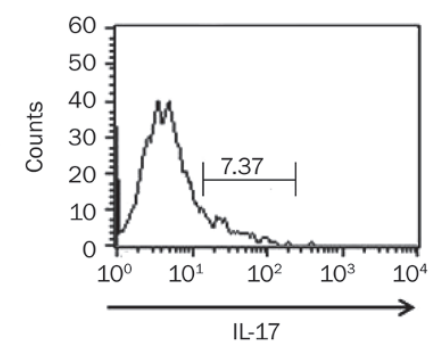

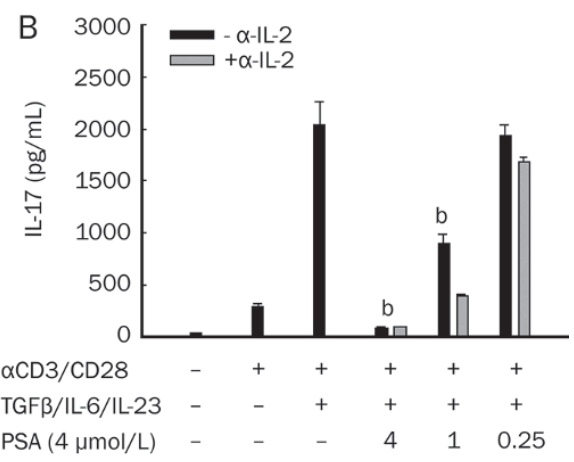

C

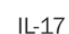

IL-17

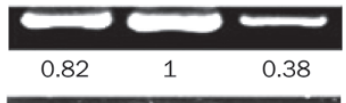

RORYt

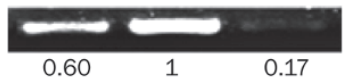

IL-23R

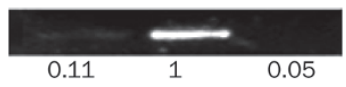

$\beta$-actin

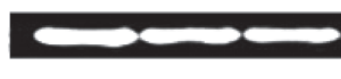

$\alpha \mathrm{CD} 3 / \mathrm{CD} 28$

TGFß/IL-6/IL-23

PSA $(4 \mu \mathrm{mol} / \mathrm{L})$
Figure 6. PSA inhibited Th17 cell differentiation in vitro. (A) Flow cytometry of CD4 ${ }^{+}$ $T$ cells stained for intracellular IL-17 to quantify the suppressive effect of PSA under Th17-polarizing conditions. Numbers above the bracketed lines indicate the percentage of cells in that area. (B) ELISA result of IL-17 in supernatants from $\mathrm{CD}^{+} \mathrm{T}$ cells in the presence of $\operatorname{PSA}(4,1$, and $0.25 \mu \mathrm{mol} / \mathrm{L})$ under Th17-polarizing conditions with or without anti-IL-2 antibody $(10 \mu \mathrm{g} / \mathrm{mL})$. The results are expressed as mean \pm SEM. ${ }^{\mathrm{b}} \mathrm{P}<0.05$ compared with vehicle control (unpaired Student's $t$-test). Three independent experiments were performed with similar results. (C) Total RNA was extracted and reverse transcribed into cDNA and the expression levels of IL17, RORyt, and IL-23R were evaluated using PCR. The numbers below each lane indicate the ratio to $\mathrm{mRNA}$ levels from vehicle-treated cells by semiquantitative analysis. Three independent experiments were performed with similar results. aimed to explain the novel mechanisms underlying PSA action and consequently provide experimental evidence for developing future clinical treatments of autoimmune diseases.

IL-6, which synergistically combines with TGF- $\beta 1$, induces the differentiation of naïve $\mathrm{CD}^{+} \mathrm{T}$ cells into Th17 cells in mice. IL-6 knockout mice are highly resistant to the development of EAE ${ }^{[21,22]}$, and IL-6 blockade inhibits the induction of myelin antigen-specific Th17 cells and Th1 cells in EAE ${ }^{[23]}$. To investigate whether PSA directly inhibited MOG-specific IL-17 production, we examined the production of IL-17 and its upstream cytokine IL-6 at different time points (onset, peak, and remission). As shown in Figure 3E, decreased production of IL-17 could be detected at all selected time points in PSAtreated group, although only the difference at the first time point (onset) reached a significant level. Meanwhile, we could only detect a transient suppressive effect of IL-6 production in the PSA-treated group at the onset (Figure 3F). Considering that IL-6 is important for the initial decision of naïve Th cells to differentiate to Th17 ${ }^{[24]}$, as well as at later time points (peak, remission), IL-6 might not be so important. Thus, we proposed that PSA acted directly on IL-17 production, but also partially acted on its upstream cytokines, such as IL-6. Then, we investigated the direct suppressive effect of PSA on Th17 cells by intracellular staining of IL- $17^{+} \mathrm{T}$ cells. Although $\mathrm{CD} 4^{+}$ $\mathrm{T}$ cells are considered the main source of IL-17, many other cells, such as $\mathrm{CD}^{+} \mathrm{T}$ cells ${ }^{[25]}$, NKT cells ${ }^{[26]}$, and $\gamma \delta \mathrm{T}$ cells ${ }^{[27]}$, plus some non-T cells, are also producers of IL-17. The existence of these cells in our experimental system might explain the proportion of CD4-IL-17 ${ }^{+}$cells in our results. The influence of PSA on other IL-17-producing cells requires further study.

We further investigated the effect of PSA on Th17 cell differentiation in vitro. However, purification of naïve $\mathrm{CD} 4^{+}$cells requires special reagents or a flow sorter and it is difficult to obtain large numbers of naïve $\mathrm{CD} 4^{+}$cells. Kopf et al ${ }^{[28]}$ had previously demonstrated that unfractionated $\mathrm{CD}^{+} \mathrm{T}$ cells mimicked naïve $\mathrm{CD} 4^{+} \mathrm{T}$ cells in the reciprocal generation of Th17 cells. Thus, we used unfractionated CD4 ${ }^{+} \mathrm{T}$ cells to investigate the effect of PSA on Th17 cell differentiation. Results demonstrated that PSA suppressed Th17 cell differentiation in a dose-dependent manner and inhibited Th17-related gene expression. It is notable that PSA treatment is also associated with the downregulation of RORyt, the retinoic acid receptor (RAR)-related transcription factor that drives Th17 cell differentiation. It will be important to determine the mechanisms by which PSA influences RORyt expression during $\mathrm{CD}^{+} \mathrm{T}$ cell differentiation. Many in vivo studies have demonstrated an absolute requirement of STAT3 for generating Th17 cells responses $^{[29]}$. STAT3 is a master regulator of this pathogenic $\mathrm{T}$ cell subtype, acting at multiple levels in vivo, including Th17 cell differentiation and cytokine production, as well as the induction of RORyt and the IL-23R ${ }^{[30]}$. Nevertheless, the main inflammatory STAT3 pathway that is potentially affected by PSA requires further investigation.

Many studies also have focused on the events caused by APCs that influence the development of Th17 cells associated with autoimmunity. IL-23, a member of the IL-12 cytokine family, plays an important role in maintaining Th17 effector function $^{[7,31]}$. In addition, IL-27, another member of the IL-12 
heterodimetric family, is a negative regulator of Th17 cell differentiation ${ }^{[20,32]}$. Because $\mathrm{CD} 4^{+} \mathrm{T}$ cells are the main source of IL-17-producing cells, we focused on the effect of PSA on T cells but not APCs. Whether PSA could influence cytokines or the signaling molecules that are generated by APCs needs further investigation.

IL-2, acting via STAT5, attenuates overproduction of IL-17, which in addition to its positive effects on Treg cells provides another mechanism to limit immune-mediated damage to the host ${ }^{[33]}$. In our in vitro system of generating Th17 cells, we observed elevated level of IL-2 in the supernatant after treatment with PSA (data not shown). We asked whether the inhibitory effect of PSA on in vitro Th17 cell differentiation was partially due to the upregulation of the IL-2/STAT5 pathway. However, the suppressive effect of PSA on IL-17 production was not abrogated in the presence of an anti-IL-2 $\mathrm{mAb}$ (Figure $6 \mathrm{~B})$. Thus, we argued that PSA inhibited Th17 cell differentiation without influencing the IL-2/STAT5 pathway. Considering the survival role of IL-2 and its critical role during cell proliferation $^{[34,35]}$, we concluded that the increased level of IL-2 detected in the supernatant after treatment with PSA might be partially due to the suppressive effect of PSA on cell proliferation.

More recently, additional fates for $\mathrm{CD}^{+} \mathrm{T}$ cells have emerged that provide more insights into the mechanisms of tolerance and immune-mediated disease. One of these new subsets of $\mathrm{T}$ cells that express the transcription factor FoxP3 is termed regulatory $\mathrm{T}$ cells (Tregs), which serve to inhibit immune responses. The ability to affect Th17/Treg polarization has attracted great clinical interest ${ }^{[36,37]}$. Indeed, some well studied compounds, such as rapamycin ${ }^{[28]}$, and retinoic acid ${ }^{[38]}$ inhibit Th17 polarization and promote FoxP3 expression. In contrast, cyclosporine A (CsA $)^{[39]}$, another widely used immunosuppressant, reduces the proportion of Tregs instead. In the present study, we found that FoxP3 mRNA expression was not upregulated in PSA-treated mice on $\mathrm{d} 12$ pi. Thus, we proposed that PSA might not influence Tregs in the treatment of EAE. However, because the expression of the FoxP3 gene does not have to correlate with the number of FoxP3-positive cells, the validation of PSA effects on Tregs needs further investigation, such as intracellular staining of FoxP3.

Recently, several reports have shown that EAE could be induced and promoted in a Th17-independent way. For example, Haak et al have demonstrated that IL-17A and IL-17F did not contribute to autoimmune neuro-inflammation in mice ${ }^{[40]}$. These findings provide new perspectives for studying the mechanisms of PSA on EAE. The influence of PSA on other important EAE-inducing/promoting factors requires further investigation.

In summary, the present study demonstrated that oral administration of PSA, an active compound that was extracted from a traditional Chinese herb $P$ sepium Bge, prevented mice from $\mathrm{MOG}_{35-55}$-induced $\mathrm{EAE}$, and its protective effects were closely linked to the direct inhibition of Th17 cells. Therefore, our results indicate that PSA has potential as a therapeutic agent for human MS.

\section{Acknowledgements}

The research work was supported by National Natural Science Foundation of China (No 20672124), Science and Technology Commission of Shanghai Municipality (№ 06DZ19721; 08XD14053; 08DZ1980200).

\section{Author contribution}

Prof Jian-ping ZUO, Prof Yi-fu YANG, Prof Wei-min ZHAO, and Prof Wei TANG designed the research; Jing ZHANG, Jia NI, and Xin LI performed the research; Zhen-hua CHEN and Ru-jun ZHANG provided the compound; and Jing ZHANG analyzed data and wrote the paper.

\section{References}

1 Chu CQ, Wittmer S, Dalton DK. Failure to suppress the expansion of the activated CD4 T cell population in interferon gammadeficient mice leads to exacerbation of experimental autoimmune encephalomyelitis. J Exp Med 2000; 192: 123-8.

2 Ferber IA, Brocke S, Taylor-Edwards C, Ridgway W, Dinisco C, Steinman $\mathrm{L}$, et al. Mice with a disrupted IFN-gamma gene are susceptible to the induction of experimental autoimmune encephalomyelitis (EAE). J Immunol 1996; 156: 5-7.

3 Iwakura $\mathrm{Y}$, Ishigame $\mathrm{H}$. The IL-23/IL-17 axis in inflammation. J Clin Invest 2006; 116: 1218-22.

4 Willenborg DO, Fordham SA, Staykova MA, Ramshaw IA, Cowden WB. IFN-gamma is critical to the control of murine autoimmune encephalomyelitis and regulates both in the periphery and in the target tissue: a possible role for nitric oxide. J Immunol 1999; 163: 5278-86.

5 Gran B, Zhang GX, Yu S, Li J, Chen XH, Ventura ES, et al. IL-12p35deficient mice are susceptible to experimental autoimmune encephalomyelitis: evidence for redundancy in the IL-12 system in the induction of central nervous system autoimmune demyelination. J Immunol 2002; 169: 7104-10.

6 Nakae S, Nambu A, Sudo K, Iwakura Y. Suppression of immune induction of collagen-induced arthritis in IL-17-deficient mice. J Immunol 2003; 171: 6173-7.

7 Langrish CL, Chen Y, Blumenschein WM, Mattson J, Basham B, Sedgwick JD, et al. IL-23 drives a pathogenic T cell population that induces autoimmune inflammation. J Exp Med 2005; 201: 233-40.

8 Veldhoen BSaM. Differentiation and function of Th17 T cells. Curr Opin Immunol 2007; 19: 281-86.

9 Ivanov, II, McKenzie BS, Zhou L, Tadokoro CE, Lepelley A, Lafaille $\mathrm{JJ}$, et al. The orphan nuclear receptor RORgammat directs the differentiation program of proinflammatory IL-17+ T helper cells. Cell 2006; 126: 1121-33.

10 Bettelli E, Carrier Y, Gao W, Korn T, Strom TB, Oukka M, et al. Reciprocal developmental pathways for the generation of pathogenic effector TH17 and regulatory T cells. Nature 2006; 441: 235-8.

11 Zhu YN, Zhao WM, Yang YF, Liu QF, Zhou Y, Tian J, et al. Periplocoside $E$, an effective compound from Periploca sepium Bge, inhibited T cell activation in vitro and in vivo. J Pharmacol Exp Ther 2006; 316: 662-9.

12 Zhu YN, Zhong XG, Feng JQ, Yang YF, Fu YF, Ni J, et al. Periplocoside $E$ inhibits experimental allergic encephalomyelitis by suppressing interleukin 12-dependent CCR5 expression and interferon-gammadependent CXCR3 expression in T lymphocytes. J Pharmacol Exp Ther 2006; 318: 1153-62.

13 Wan J, Zhu YN, Feng JQ, Chen HJ, Zhang RJ, Ni J, et al. Periplocoside $A$, a pregnane glycoside from Periploca sepium Bge, prevents 
concanavalin A-induced mice hepatitis through inhibiting NKT-derived inflammatory cytokine productions. Int Immunopharmacol 2008; 8: 1248-56.

14 Ni J, Shu YY, Zhu YN, Fu YF, Tang W, Zhong XG, et al. COX-2 inhibitors ameliorate experimental autoimmune encephalomyelitis through modulating IFN-gamma and IL-10 production by inhibiting T-bet expression. J Neuroimmunol 2007; 186: 94-103.

$15 \mathrm{Fu}$ YF, Zhu YN, Ni J, Zhong XG, Tang W, Re YD, et al. A reversible S-adenosyl-L-homocysteine hydrolase inhibitor ameliorates experimental autoimmune encephalomyelitis by inhibiting $T$ cell activation. J Pharmacol Exp Ther 2006; 319: 799-808.

16 Fitzgerald DC, Ciric B, Touil T, Harle H, Grammatikopolou J, Das Sarma J, et al. Suppressive effect of IL-27 on encephalitogenic Th17 cells and the effector phase of experimental autoimmune encephalomyelitis. J Immunol 2007; 179: 3268-75.

17 Kroenke MA, Carlson TJ, Andjelkovic AV, Segal BM. IL-12- and IL-23modulated $T$ cells induce distinct types of EAE based on histology, CNS chemokine profile, and response to cytokine inhibition. J Exp Med 2008; 205: 1535-41.

18 Yang YF, Mukai T, Gao P, Yamaguchi N, Ono S, Iwaki H, et al. A nonpeptide CCR5 antagonist inhibits collagen-induced arthritis by modulating $T$ cell migration without affecting anti-collagen $T$ cell responses. Eur J Immunol 2002; 32: 2124-32.

19 Veldhoen M, Hocking RJ, Atkins CJ, Locksley RM, Stockinger B. TGFbeta in the context of an inflammatory cytokine milieu supports de novo differentiation of IL-17-producing T cells. Immunity 2006; 24 : 179-89.

20 Stumhofer JS, Laurence A, Wilson EH, Huang E, Tato CM, Johnson LM, et al. Interleukin 27 negatively regulates the development of interleukin 17-producing T helper cells during chronic inflammation of the central nervous system. Nat Immunol 2006; 7: 937-45.

21 Okuda Y, Sakoda S, Bernard CC, Fujimura H, Saeki Y, Kishimoto T, et al. IL-6-deficient mice are resistant to the induction of experimental autoimmune encephalomyelitis provoked by myelin oligodendrocyte glycoprotein. Int Immunol 1998; 10: 703-8.

22 Samoilova EB, Horton JL, Hilliard B, Liu TS, Chen Y. IL-6-deficient mice are resistant to experimental autoimmune encephalomyelitis: roles of IL- 6 in the activation and differentiation of autoreactive T cells. J Immunol 1998; 161: 6480-6.

23 Serada S, Fujimoto M, Mihara M, Koike N, Ohsugi Y, Nomura S, et al. IL-6 blockade inhibits the induction of myelin antigen-specific Th17 cells and Th1 cells in experimental autoimmune encephalomyelitis. Proc Natl Acad Sci U S A 2008; 105: 9041-6.

24 Harrington LE, Hatton RD, Mangan PR, Turner H, Murphy TL, Murphy $\mathrm{KM}$, et al. Interleukin 17-producing CD4+ effector T cells develop via a lineage distinct from the $T$ helper type 1 and 2 lineages. Nat Immunol 2005; 6: 1123-32.

25 Ciric B, El-behi M, Cabrera R, Zhang GX, Rostami A. IL-23 drives pathogenic IL-17-producing CD8+ T cells. J Immunol 2009; 182:
5296-305.

26 Yoshiga Y, Goto D, Segawa S, Ohnishi Y, Matsumoto I, Ito S, et al. Invariant NKT cells produce IL-17 through IL-23-dependent and -independent pathways with potential modulation of Th17 response in collagen-induced arthritis. Int J Mol Med 2008; 22: 369-74.

27 O'Brien RL, Roark CL, Born WK. IL-17-producing gammadelta T cells. Eur J Immunol 2009; 39: 662-6.

28 Kopf H, de la Rosa GM, Howard OM, Chen X. Rapamycin inhibits differentiation of Th17 cells and promotes generation of FoxP3+ T regulatory cells. Int Immunopharmacol 2007; 7: 1819-24.

29 Liu X, Lee YS, Yu CR, Egwuagu CE. Loss of STAT3 in CD4+ T cells prevents development of experimental autoimmune diseases. J Immunol 2008; 180: 6070-6.

30 Harris TJ, Grosso JF, Yen HR, Xin H, Kortylewski M, Albesiano E, et al. Cutting edge: an in vivo requirement for STAT3 signaling in TH17 development and TH17-dependent autoimmunity. J Immunol 2007; 179: 4313-7.

31 Aggarwal S, Ghilardi N, Xie MH, de Sauvage FJ, Gurney AL. Interleukin23 promotes a distinct CD4 T cell activation state characterized by the production of interleukin-17. J Biol Chem 2003; 278: 1910-4.

32 Batten M, Li J, Yi S, Kljavin NM, Danilenko DM, Lucas S, et al. Interleukin 27 limits autoimmune encephalomyelitis by suppressing the development of interleukin 17-producing T cells. Nat Immunol 2006; 7: 929-36.

33 Laurence A, Tato CM, Davidson TS, Kanno Y, Chen Z, Yao Z, et al. Interleukin-2 signaling via STAT5 constrains T helper 17 cell generation. Immunity 2007; 26: 371-81.

34 Moriggl R, Topham DJ, Teglund S, Sexl V, McKay C, Wang D, et al. Stat5 is required for IL-2-induced cell cycle progression of peripheral $T$ cells. Immunity 1999; 10: 249-59.

35 Van Parijs L, Refaeli Y, Lord JD, Nelson BH, Abbas AK, Baltimore D. Uncoupling IL-2 signals that regulate T cell proliferation, survival, and Fas-mediated activation-induced cell death. Immunity 1999; 11: 281-8.

36 Bluestone JA. Regulatory T-cell therapy: is it ready for the clinic? Nat Rev Immunol 2005; 5: 343-9.

37 Bettelli E, Oukka M, Kuchroo VK. T(H)-17 cells in the circle of immunity and autoimmunity. Nat Immunol 2007; 8: 345-50.

38 Elias KM, Laurence A, Davidson TS, Stephens G, Kanno Y, Shevach EM, et al. Retinoic acid inhibits Th17 polarization and enhances FoxP3 expression through a Stat-3/Stat-5 independent signaling pathway. Blood 2008; 111: 1013-20.

39 Wang H, Zhao L, Sun Z, Sun L, Zhang B, Zhao Y. A potential side effect of cyclosporin $A$ : inhibition of $C D 4^{+} C D 25^{+}$regulatory $T$ cells in mice. Transplantation 2006; 82: 1484-92.

40 Haak S, Croxford AL, Kreymborg K, Heppner FL, Pouly S, Becher B, et al. IL-17A and IL-17F do not contribute vitally to autoimmune neuroinflammation in mice. J Clin Invest 2009; 119: 61-9. 